Luis D. Cruz Ocampo

\title{
Nuestros Poetas \\ por Armando Donoso
}

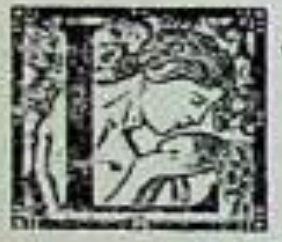

A Antologia que acaba de publicar Armando Donoso presenta omisiones que acaso hubiera sido mejor evitar. Pero no obstante esta circunstancia, me parece que el mérito general de la obra no resulla en definitiva perjudicado. En efecto, se nos ofrece una vista panorámica de la evolución de la poesía nacional: y los poetas cuyas obras no aparecen en el texto presentan caracteristicas espirituales que ya están scrialadas con la labor de otros poetas. Sin embargo. es evidente que cabe discusión acerca de qué autor puede representar mejor que otro una corriente artistica determinada. Pero aún en la hipótesis de que se llegaran a aceptar algunas de esas posibles sustituciones, las orientaciones ya marcadas en la colección no cambiarian sino que resultarian reafirmadas.

Donoso ha dividido el desarrollo de la poesia nacional en tres épocas que marca con otras tres fechas precisas del calendario. No pretendo, en modo alguno, sostener que esa división cronológica no corresponde con mayor o menor aproximación a la verdad. Pero de todos modos a titulo de simple curiosidad quiero señalar otra división de las muchas que pueden hacerse en el camino de la poesía nacional. Ateniéndome, pues, a los asuntos o temas que preocupan a los poetas y al modo de desarrollarlos, o más exactamente a los fenómenos de la sensibilidad $y$ de la inteligencia que presentan en sus obras puede dividirse la historia de nuestra poesía en tres periodos. a saber: el primero, desde Pablo Garriga hasla Gustavo Valledor Sánchez: el segundo, desde Julio Vicuña Cifuentes hasta Antonio Bórquez Solar: y el tercero, desde Magallanes hasta hoy. En esta época deberia incluirse, a mi entender, a Luis Felipe Contardo que Donoso coloca entre los de su primera época, o sea entre los anteriores a Magallanes. No aparece claramente manifiesta la razón que haya tenido el autor para hacer la clasificación de Contardo. En efecto, si la base de la clasificación es la fecha del nacimiento. Contardo debe quedar después de Magallanes: igual cosa sería si la base es la fecha de la primera publicación. Quedaria suponer que se ha hecho una clasificación 
en atención a los asuntos que interesan al poeta. pero no es este el sistema que ha aplicado el autor en el resto de la obra.

La primera época estaria caracterizada por su falta de espíritu poético propiamente dicho. Los escritores parecen no advertir los fenómenos de su vida inlerna y ni aủn saben ver la vida de la naturaleza, sino como accesoria para adornar sus asuntos principales. La segunda época empezaria con Julio Vicuña Cifuentes cuya sensibilidad es afectada por asuntos muy diversos de los que preocupaban a sus antecesores, como lo comprueban los temas de sus obras. Desde luego aparece el poeta preocupado por el arduo problema de la finalidad de la vida: manifiesta interés por el dolor humano y su sensibilidad alcanza hasta llevarle a interesarse por la vida de los animales, a quienes consagra algunos de sus mejores trabajos. Comienzan también en esta época a aparecer los temas de indole social en los que el poeta aboga por el mejoramiento del trabajador o se siente atraído por lo que hay de heróico y resignado en su existencia. Lillo canta. entonces, al arponero: Diego Dublé Urrutia, al minero, los amores de los pescadores, las tristezas de los indios despojados de sus tierras, las fiestas populares. como la Bendición de San Pedro y otras. Contreras inicia la interpretación del paisaje como un estado de alma. Todos tienen de común entre sí un cierto tono o resabio romántico que no aparece en los poetas del último periodo.

Desde Magallanes en adelante parece que cambia totalmente la sensibilidad de los poefas. Sería sin duda demasiado extenso el detenerme a examinar aqui la obra de cada uno de los treinta y ocho o más poetas que abarca la antología de Donoso a contar desde Magallanes hasta Romeo Murga. Dero el repasar, aunque sea ligeramente, su obra es bastante para apreciar. en lineas generales. la enorme diferencia que existe entre los autores del segundo y tercer períodos. en lo que se refiere a la variedad y naturaleza de los asuntos que afectan su sensibilidad. La única excepción en este grupo la constituye Víctor Domingo Silva que es indudablemente un romántico: pero un romántico especial que sólo tiene del viejo romanticismo el impulso lírico. la palabra exaltada, el gesto heróico y el espiritu bravio y acometedor; pero, al mismo tiempo en algunas de sus más bellas composiciones aparece la delicada sensibilidad, que caracteriza a los poetas de este grupo.

Donoso ha formado un tercer grupo con los poetas que se han dado a conocer a partir desde 1920 . Pero si se juzga a estos autores por los fenómenos de su sensibilidad, no creo que pueda llegar a establecerse diferencia esencial alguna. Por lo menos los trabajos que aparecen en la antologia no dan motivo. según este criterio. para hacer separación alguna con el grupo anterior en el que estän Magallanes, Gabriela Mistral, Pedro Prado. Ernesto Guzmán. Jorge Hübner, Domingo Gómez Rojąs. Angel Cruchaga. Juan Guzmán Cruchaga y otros.

El interesante discurso sobre la evolución de la poesía chilena que ha puesto Donoso a modo de prólogo a su Antologia toca diversos problemas de muy alto 
valer para los estudios literarios. Hasta donde - se pregunta el autor-el ambiente de un pueblo determina su producción espiritual?. Parece que Donoso no atribuye al ambiente sino un efecto restringido, con lo que, evidentemente, coloca la cuestión en su verdadero terreno. La fuerza creadora que es la deferminante reside esencialmente en el individuo y no en la masa o en el medio físico. No importa esto negar influencia del medio sino establecer la exacta relación que tiene con el autor. El medio es causa pero es también resultado. Una causa. dice Bourget, pues las cosas ambientes influyen prolundamente sobre los caracteres, y desde el amoblado hasta el clima no hay nada que no entre en la serie infinita de las pequeñas impresiones que forman el yo: un resultado, porque la persona humana tiende a representarse en las cosas que la rodean y a prolongarse en ellas. La pieza en que vive un hombre llega asi a ser la figura externa de sus hábitos y de sus actitudes (1). Además, la influencia de estos factores externos no alcanzan a modificar lo esencial del carảcter debidamente formado. Su acción será, pues. variable según que obre sobre individuos de una personalidad fuerte $y$ bien definida o sobre uno de carácter débil y borroso. Asi será muy escaso su ascendiente sobre el hombre de genio, o sea el creador; un poco más marcado sobre el simplemente genial. o sea sobre el que se dedica a interpretar de algún modo obras creadas por otro; y más intensa aún sobre el genialoideo o sea sobre el que tiene todo el aspecto externo de un creador pero en realidad no crea nada. Hay por lin otros individuos de temperamento menos resistente que sucumben totalmente a la influencia del ambiente.

Trasladando esla misma cuestión a otro terreno, podremos apreciar la influencia del ambiente social sobre individuos de temperamento morboso. Podemos ver que el hombre normal resiste las solicitaciones de un medio ambiente dañoso: y que ciertos tipos de criminales no son accesibles a la menor influencia moralizadora de un medio ambiente sano. Estos fipos no son, pues, modificados por el ambiente. En ambos casos tenemos que, con las debidas diferencias la influencia del ambiente no se hace senfir sino en proporciōn inversa a la intensidad del carácter del sujeto. El genio creador no puede. en consecuencia, ser influido sustancialmente ni menos anulado por la hostilidad del medio.

Por lo contrario, el genio creador se forma ambiente por medio de todos los espiritus cuya organización es virtualmente semejante a la suya. Su ambiente espiritual puede así no coincidir con el medio ambiente social que le rodea. La historia literaria está llena de casos que podrian servir de ilustración a estos asertos. Pero, para no citar sino los más recientes, basta recordar el caso de Heine tan poco estimado en Alemania como celebrado en Francia; el de Poe que encuentra también en Francia mejor y más cordial acogida que en su propio pais donde las gentes suelen mirarle con cierto desdén. Asi, pues, una literatura no revela a la colectividad donde ocasionalmente ha sido producida, sino en cuanto esa colectividad adopta y admira esa literatura y se siente representada en ella. En efeclo, todo escritor precipita, por decirlo asi en términos de qui-

(1) Bourget-Essais de Pyychologie Contemporoine, fomo II, p6g. 200, Plon, 1920. 
mica, a todos los individuos que les son afines por sus calidades espirituales. Por tanto, en virtud de esta ley de la similitud psicológica, quien entiende al Dante posee condiciones espirituales análogas a las del poeta florentino. Sin embargo, el admirador no podrá jamás escribir la Divina Comedia porque sus facultades son simplemente receptivas o pasivas y no activas o con virtud creadora. Esta misma ley de la similitud psicológica nos permite, además. juzgar las condiciones del autor por las de sus admiradores. Por ejemplo. es evidente que si un autor es el preferido por los cocheros o choleres, o por otras gentes de este mismo grado de cultura, es porque ellos encuentran alli su ambiente, sus pasiones groseras, sus apetitos bajos. sus inclinaciones violentas: en una palabra, su ordinariez de espiritu. Si fales condiciones no estuvieran alli aquellas personas no podrian sentirse atraidas y ni siquiera entenderian la obra.

De aqui también que para juzgar con acierto una obra de arte no es necesario, en modo alguno, haber producido obras semejantes. Es frecuente oir decir a los poetas que para juzgar un verso es preciso ser también poeta, en el sentido de haber escrito o publicado versos. Igual cosa suele repetirse acerca de las condiciones para criticar o estudiar una obra teatral o una novela. Tales afirmaciones son tofalmente erróneas si con ellas se quiera decir que el crítico debe haber escrito versos, obras teatrales o novelas antes de emitir su opinión. Sólo puede aceptarse aquello de para juzgar una poesia es necesario ser poeta en el sentido de la similitud psicológica. De este modo llegaremos a ver que en muchos casos puede haber mayor diferencia espiritual, y por tanto mayor incomprensión mutua, entre dos poefas, dos novelistas o dos dramaturgus que entre uno de ellos y el critico que juzga su obra.

Finalmente. para terminar estos comentarios acerca de las relaciones del artisfa con el medio, conviene recordar un caso que nosotros hemos podido apreciar en todos sus detalles. Quiero referirme al caso de Rubén Darío cuya sensibilidad artistica y cuyo talento no pueden derivar del medio en que vivió primero en Nicaragua y después en Chile. Más aún, su temperamento poético es manifiestamente opuesto al medio: y no obstante. consiguió prosperar y acrecentarse. aunque fuera entre las burlas de unos. la incomprensión de otros y la indiferencia de fodos. También conviene llamar la atención hacia el hecho de que en un mismo medio se producen los más variados y contrarios temperamentos de escritores. Es evidente que un solo medio no bastaria para explicar la presencia de autores cuyas cualidades fundamentales son contrarias. La literatura de todos los tiempos confirma el aserto de que hay tantos ambientes como talentos capaces de revelarlos o determinarlos.

La historia de todo el siglo XIX-dice Donoso-no es más que un largo ensayo que no define su carácter. En perfecto acuerdo con esta idea cabe, sin embargo, preguntarse si en este primer cuarto del siglo XX ha alcanzado la poesia en Chile aspectos particulares que le den un carácter especial. Sería di- 
ficil contestar afirmativamente a esta cuestion, pues, aunque tenemos verdaderos y altos poetas sus producciones, en conjunto. no logran interesar sino a un grupo más o menos amplio o reducido, pero que siempre es el mismo. Por otra parte ya se han hecho esfuerzos para injertar el espiritu de chilenidad en nuestra literatura. El mismo Donoso constata el fracaso de semejante empeño que no pasó más allá de proporcionar decoraciones fastidiosas para cuadros interminablemente repetidos. Por suerte, se vió luego que todo aquello era falso. y cada cual recobró su liberlad de acción: y fué a buscar su propia personalidad por un camino diferente.

El hecho de que los poetas actuales no logren interesar y representar a la colectividad nacional es un verdadero motivo de elogios para ellos. Sería inferir una gratuita y terrible ofensa a Gabriela Mistral, Prado. Ernesto Guzmán. Jorge Hübner. Cruchaga Santa María, y otros muchos el suponerles afinidades psicológicas con la colectividad nacional en general. Durante mucho tiempo todavía esta masa vulgar y analfabeta no podrá tener otros representantes que sus diputados.

Por otra parte, parece que nosotros no poseemos elementos que puedan servir de base a una producción caracteristica en la que haya una sensibilidad propia. No hemos tenido esa poesía primitiva que guarda modos originales de ver y sentir la vida a través de mitos o fábulas poéticas. Nuestra literalura ha sido rudimentaria pero nunca primitiva. Por lo contrario, desde los más lejanos tiempos hemos tenido que vivir necesariamente de las imitaciones; y hemos sido traidos y llevados por las corrientes de las modas como un cuerpo sin dirección o un individuo débil de carácter.

Donoso disculpa la pobreza de nuestra producción artistica durante el siglo pasado con diversas razones que, no obstante su calidad y número no alcanzan a disimular la dolorosa verdad de que nuestra aridez artistica se debe no al medio sino a la falta de hombres con sensibilidad de poetas. En este punto Donoso se siente empujado a atribuir al medio un efecto más poderoso que el que realmente le corresponde, según lo que ya llevamos dicho. Estima que no era posible esperar una literatura floreciente. o siquiera de mediano valer, en momentos en que se vivía con el arma al brazo, en lucha sostenida con los indigenas indomables. Ni cuando el pais estaba preocupado de darse sus leyes civiles o politicas, o se atareaba en la organización de sus escuelas o en el establecimiento de sus ferrocarriles. Mas, me parece que todos estos factores bien pudieron dar a los espírifus una orientación deferminada pero no suprimir la vida espiritual. Por otra parte, los pueblos no han esperado vivir en paz y sin preocupaciones para permitir que nacieran hombres de sensibilidad artística extraordinaria. En todas las épocas han aparecido estos seres privilegiados sin sujeción a las tareas que realizaba el pueblo. Si asi no hubiera sido, los pueblos primitivos que vivian en constante lucha armada no habrian podido tener los poetas que cantaron sus hazañas o idearon sus fábulas. Especialmente Grecio vivió en continuas guerras: además, su pueblo tomaba realmente parte en la 
discusión de las leyes; sin embargo, pudieron producir los más altos artistas de todos los tiempos.

Nosotros. en cambio, solo podemos hablar mefafóricamente de que estábamos ocupados en redactar nuestros códigos o en fundar nuestras escuelas o en abrir vias férreas o en combatir a los araucanos. La verdad es que jamás nos preocupó la legislación, y no hemos tomado parte alguna en la discusión de las reglas del comodato o en las atribuciones de los poderes públicos. Esas fueron preocupaciones de dos o tres personas que lo hicieron todo. Más aủn. la legislación despertaba tan escaso interés en los individuos que las comisiones que designó el Gobierno para que redactaran el Código Civil se fueron reduciendo poco a poco hasta que no quedó más que don Andrés Bello. Ahora bien. épor qué razón mientras Bello reglamentaba las acciones posesorias los demás habitantes del pais no tenian tiempo para manifestar sus aficiones artisticas y para cultivarlas como les diera la gana? ¿Por qué los demás no tenían tiempo para eso cuando lo tenia don Andrés Bello, el único que se ocupaba de la legislación, para hacer una obra literaria considerable? ¿De qué modo la expedición liberfadora al Perú o los afanes de Sarmiento que organizaba la instrucción primaria pudieron hacer desaparecer o ahogar en germen la vida del genio creador.

Poseemos un medio ambiente fisico muy semejante al de la Grecia clásica: clima moderado. territorio ampliamente bañado por el mar. tierras poco fértiles. efc., ete. Tenemos entre otras ventajas la de que disfrutamos de paz; y tenemos un sistema político que no nos obliga a tomar parte en la discusión de los asuntos del Estado. Sin embargo. mientras los propios legisladores griegos cultivaban las artes nosotros no tenemos oportunidad de mostrar nuestros gustos artisticos y educar nuestro espiritu, porque dos o tres personas están, en el silencio de sus gabinetes redactando leyes civiles o discurriendo acerca de la organización de la instrucción primaria. Todas las literaturas se han formado no obstante las guerras o los movimientos o preocupaciones del pueblo; y han reflejado estas inquietudes o aquellas glorias. En el estado social caótico de la Edad Media, cuando las gentes vivían bajo la amenaza de los saqueos y de las rapiñas de los señores, los poetas iban, no obstante, de castillo en castillo cantando las hazañas de los guerreros o las angustias de sus almas. No me parece, pues. que en el medio ambiente pueda hallarse la razón de nuestra lamentable aridez espiritual. Ahora bien ¿cuáles serán, entonces, las causas que han impedido la producción de individuos de sensibilidad artistica desarrollada? Es evidente que si no están en el medio ambiente tendrán que estar en el sujefo. $\mathrm{Y}$ he aquí el problema que acaso pueda resolver satisfactoriamente la etnologia. Esta nos dirá hasta qué punto nos han sido desfavorables los cruzamientos con raza indigena que han producido la población del pais. Tal vez se pueda calcular el efecto deplorable que puede haber tenido para la intelectualidad de la raza la circunstancia de que los conquistadores españoles se reprodujeran en mujeres araucanas o indigenas, ya que la mujer. como el elemento conservador de la especie, trasmite sus características raciales a la descendencia. Quizá si encontramos en- 
tonces que para llegar a la capacidad artistica ha sido necesario ir eliminando generación tras generación las influencias funestas de una raza manifiestamente inferior desde cste punto de vista.

En ofra parte de su discurso formula Donoso diversas apreciaciones muy exactas sobre los valores artisticos que nos ofrece el período que llama con acierto snuestra edad media ni enorme ni delicada., Luego traza, con pleno dominio del asunto, el camino vacilante del gusto artístico en el pais, hasta llegar a los tiempos actuales que no podrian ser llamados de Renacimiento sino únicamente de nacimiento. Acaso ahora no diria Menéndez y Pelayo que no somos sino un pais de juristas y de historiadores. En efecto nuestros historiadores se van extinguiendo: nuestros legisladores desaparecieron hace ya muchos años; y nuestros poetas empiezan ahora a endulzar el aire patrio agitado antes por las tempestades. los ciclones y. los volcanes que manejaba Dedro Antonio González.

Ha hecho Donoso una obra muy útil al imponerse la tarea de esta Antologia que solo èl. con las cualidades de trabajador extraordinario y estusiasta. que le son propias, podía llevar a cabo cumplidamente. La mayor parte de los lectores no siempre se toma el trabajo de pensar la enorme suma de labor que representa la confección de una obra como esta. Acaso se cree que solo se trata de reunir materialmente los trabajos de todos o de la mayor parte de los poetas. Pero no se tiene en cuenta que la selección importa un trabajo crítico lento y dificil de desarrollar. Luego de encontradas las orientaciones más definidas de la literatura será preciso seleccionar de entre las obras de cada poeta aquellas que representan más claramente sus tendencias espirituales. Solo después de esa enorme labor es posible presentar una vista panorámica de la vida de la poesía, como la que nos ha presentado Donoso.

Después de leer su discurso preliminar. lleno de le y cálido de entusiasmo. se llega a pensar que acaso esté lejos todavia el dia terrible anunciado por Renan en que el artista será una cosa inútil. Las ideas y los conocimientos cientificos en vez de destruir el espiritu artístico van permitiendo enriquecerlo cada vez más con las más variadas solicilaciones. $Y$ ya van corridos muchos años desde aquel en que Keats, al final de un banquete memorable, invitó a los asistentes a brindar por la execración de la memoria de Newton que habia quitado a los poetas el encanto misterioso del arco iris. Mas los poetas sin tener ya aquel arco maravilloso siguen lanzando hacia lo infinito las flechas cada vez más agudas de su sensibilidad. 